\title{
Detection of CTX-M, TEM and SHV Genes in Gram Negative Bacteria Isolated from Nosocomial Patients at Port Sudan Teaching Hospital
}

\author{
Abd Elrahman Mustafa Abd Elrahman Osman, Shingray Osman Hashim, \\ Mohammed Abdall Musa, Omer Mohammed Tahir
}

Medical Laboratory Sciences Division, Port Sudan Ahlia College, Port Sudan, Sudan

Email address:

abdo_rahman96@hotmail.com (A. E. M. A. Osman)

\section{To cite this article:}

Abd Elrahman Mustafa Abd Elrahman Osman, Shingray Osman Hashim, Mohammed Abdall Musa, Omer Mohammed Tahir. Detection of CTX-M, TEM and SHV Genes in Gram Negative Bacteria Isolated from Nosocomial Patients at Port Sudan Teaching Hospital. European Journal of Clinical and Biomedical Sciences. Vol. 3, No. 6, 2017, pp. 101-108. doi: 10.11648/j.ejcbs.20170306.11

Received: October 4, 2017; Accepted: October 30, 2017; Published: November 15, 2017

\begin{abstract}
The presence of ESBLs in many Gram negative strains are of serious concern, since these organisms are the most common cause of different human infections. ESBL positive phenotypically were tested for the presence of ESBL encoding genes using PCR with specific primers for the detection of CTX-M, TEM and SHV genes, then the amplicons were sequenced to characterized gene content. The presence of CTX-M, TEM and SHV genes was confirmed in $6588 /(73.9 \%)$ of the isolates. The ESBL genes were detected in 47 Escherichia coli, 14 Klebsiellapneumoniae, 2 Proteus mirabilis, 1 Serratiaodotifera and 1 Enterobactersakasaki. The nucleotide sequences were subjected to BLAST for sequences similarity and homology.
\end{abstract}

Keywords: E. coli, K. Pneumoniae, ESBLs, CTX-M Genes, TEM Gene, SHV Genes, Sudan

\section{Introduction}

ESBL enzymes are plasmid borne and they have evolved from point mutations which altered the configuration of the active site of the original and long known $\beta$-lactamases, which have been designated as (TEM-1, TEM-2, and SHV1). Although most of the ESBLs are mutants of the TEM and the SHV enzymes, the CTX-M type beta lactamases have become more important. The CTX-M type of enzyme constitutes a distinct lineage of the molecular class A $\beta$ lactamases, which are a rapidly growing group [1].

Since the first description of plasmid-mediated extended spectrum beta lactamase (ESBL) in 1983, The ESBLproducing gram-negative organisms have posed a significant threat to hospitalized patients due to their hydrolyzing activity against extended spectrum cephalosporins often employed in the treatment of hospital-acquired infections. Detection of organisms harboring ESBLs provides clinicians with helpful information. Treatment of infections caused by ESBLproducing organisms with extended-spectrum cephalosporins or aztreonam may result in treatment failure even when the causative organisms appear to be susceptible to these antimicrobial agents by routine susceptibility testing [2]. In addition, patients colonized or infected with ESBL-producing organisms should be placed under contact precautions to avoid hospital transmission. These benefits warrant the detection of ESBL-producing organisms in clinical laboratories [1].

The ESBLs are derivatives of common $\beta$-lactamases (TEM and SHV $\beta$-lactamases) that have undergone one or more amino acid substitutions near the active site of enzyme, thus increasing their affinity and the hydrolytic activity against third generation cephalosporins and other $\beta$-lactam antibiotic. Extensive use of newer generation cephalosporins has been the strong factor for the evolution of newer B-lactamases such as ESBLs. The later are encoded by transferable conjugative plasmids, which often code resistance determinants to other antimicrobial agents such as aminoglycosides. These conjugative plasmids are responsible for the dissemination of resistance to other members of Gram negative bacteria in hospitals and in the community [3].

The development of antimicrobials resistance can be viewed as a global problem in microbial genetic ecology. It is a very complex problem to study, let alone solve, due to the geographic scale, the variety of environmental factors and the vast number 
and diversity of microbial agents. The ESBLs continue to be a major problem in clinical setups worldwide, conferring resistance against extended spectrum cephalosporins [4].

ESBL producing bacteria may not be detectable by routine disk diffusion susceptibility test, leading to inappropriate use of antibiotics and treatment failure [5].

The presence of an ESBLs-producing organism in a clinical infection can cause significant treatment problems because ESBL-mediated resistance may result in treatment failure if any of the third generation cephalosporins (e.g. ceftazidime, cefotaxime, and cefttriaxone) or a monobactum (aztreonam) are used [6]. ESBL-producing organisms may also be difficult to detect because of the effect of their different levels of activity against various cephalosporins, thus making the choice of which cephalosporin to test critical. If an ESBL-producer is detected, it should always be reported as resistant to the penicillins, cephalosporins, and monobactams even if in vitro test results indicate susceptibility, since these may fail in treatment [7].

The ESBL producers are becoming more complex and diverse. This will create challenges for those involved in detection of ESBLs in clinical microbiology. However, many clinical laboratories are facing problems in detecting extended-spectrum beta-lactamases (ESBLs). Failure to detect these strains may contribute to uncontrolled spread of nosocomial infections and sometime therapeutic failures. Clinical laboratories need to have adequate facilities to provide a clinically relevant antibiotic testing in hospitals where antibiotic resistance is encountered. Nosocomial antibiotic susceptibility may become necessary and need to be carefully considered in combination with clinical data [8].

\section{Materials \& Methods}

\subsection{Bacterial Isolates}

Four hundred bacterial isolates were obtained from various clinical specimens including Urine, Blood, Wound swab, Ear swab and Miscellaneous body fluids were collected from infected patients at Port Sudan Teaching hospital. The microbiology laboratory proceeds the specimens for the isolation and identification of significant bacterial pathogens following standard conventional procedures $[8,10]$.

Specimens of urine and miscellaneous body fluids were collected from the patients into sterile plastic containers and were transported to the microbiology laboratory and they were processed immediately for detection of pathogenic Gramnegativebacteria. However, the blood samples were extracted under aseptic condition and transferred immediately to sterile bottles containing brain heart infusion broth. Specimens from ear and wounds were taken by swabs, then placed on transport media and were analyzed as soon as possible.

\subsection{Isolation and Identification of Gram-negative Bacilli}

Isolation and identification of gram-negative bacilliwere carried out in a systemic way according to standard microbiological methods $[9,10]$. A general procedure for isolated bacteria included isolation, identification, antimicrobial susceptibility testing and screening to presence of nosocomial isolates expressing an extended-spectrum beta-lactamaseas (ESBLs) by detection of reduced zone of inhibition around the third generation cephalosporins disc as recommended by the Clinical and Laboratory Standards Institute (CLSI). These isolates were confirmed for phenotypic ESBL production by the double disc synergy test (DDST) and the confirmatory double disc diffusion test (DDDT) and then were further confirmed by genotypic method (PCR) [11].

\subsection{Cultivation of Specimens}

Isolation of Gram-negative bacteria from specimens of urine was done by culturing directly onto CLED, MacConkey and Blood agar plates (Oxoid, Basingstoke England), using sterile nichrome wire calibrated loop. While the isolation of clinical specimens of body fluids was done by culturing directly onto MacConkey and Blood agar plates. The isolation of Gramnegative bacteria from clinical specimens of the ears and wound swabs was done by inoculating directly onto MacConkey agar plates by streaking the swabs onto a small area of the plate. Then the sterile loop was used for cross-streaking to spread the inoculum over the surface of the plate to obtain single colonies. Specimen of blood was received in the microbiology laboratory in a $25 \mathrm{ml}$ brain-heart infusion broth. The bottles were then incubated aerobically overnight at a temperature of $37^{\circ} \mathrm{C}$. After overnight incubation, the blood cultures were then subcultured on blood and Macconkey agar plates (first subculture). The plates were then incubated overnight under aerobic conditions. On the third day, the first subcultures were observed for growth, and any growth identified. The samples that did not record any growth were re-incubated for another 24 hours under the same conditions. Up to three subcultures were performed similar to the procedure mentioned above if there was no growth from previous subcultures [10].

All cultured plates were incubated aerobically for 24 hours at $37^{\circ} \mathrm{C}$ and were examined for countable colonies. Each single significant growth of Gram-negative bacteria isolates were identified on the basis of cultural characteristics, gram stains, oxidase test and conventional biochemical tests, then confirmed by API 20E identification system (biomerieux Marcy-I'Etoile, France). Culture plates which yielded more than two organisms per specimen were excluded from the study.

\subsection{Antimicrobial Susceptibility Test}

Antimicrobial susceptibility testing of Gram negative bacteria isolates was performed on Mueller-Hinton agar plate (Oxoid, Basingstoke England) by the Kirby-Bauer disk diffusion method following the CLSI recommendations. Allisolates were tested for their susceptibility against 14 antimicrobial agents including; amikacin $(30 \mu \mathrm{g})$, amoxicillin $(10 \mu \mathrm{g})$, amoxicillin-clavulanic acid $(30 \mu \mathrm{g})$, ceftazidime $(30$ $\mu \mathrm{g})$, ceftriaxone $(30 \mu \mathrm{g})$, cefuroxime $(30 \mu \mathrm{g})$, chloramphenicol $(30 \mu \mathrm{g})$, ciprofloxacin $(5 \mu \mathrm{g})$, gentamicin 
(10 $\mu \mathrm{g})$, nalidixicacid $(30 \mu \mathrm{g})$, nitrofurantoin $(50 \mu \mathrm{g})$, tetracycline $(30 \mu \mathrm{g})$, tobramicin $(10 \mu \mathrm{g})$ and trimethoprimsulfamethoxazole $(25 \mu \mathrm{g})$, (Liofilchem Co. Italy). Standardized inoculum conforming to 0.5 McFarland standard turbidity of each isolate was inoculated on two Mueller-Hinton agar plates using a sterile cotton swab by streaking the swab over the entire sterile agar surface 3 times. Then onto each plate, 8 to 9 antimicrobial disks were placed at the recommended distance from each other. All plates were aerobically incubated at $37^{\circ} \mathrm{C}$ for 18 hours before the zone sizes were recorded. E. coli ATCC 25922, which were obtained from the American Type Culture Collection was used as control strains and tested each time when susceptibility testing was performed. Test results were only validated in the cases where inhibition zone diameters of the control strains were within performance range in accordance to CLSI guidelines [11].

\subsection{Phenotypic Detection of ESBLs}

\subsubsection{ESBL Screening Tests}

Screening test was carried out simultaneously with antibiotics sensitivity tests. Screening test was carried out on Muller Hinton agar plates which were seeded by bacterial suspension as mentioned previously. Antibiotics discs,

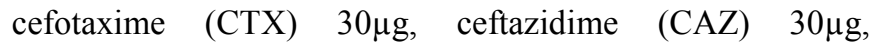

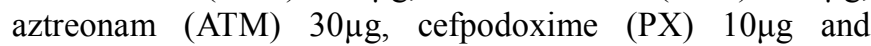
ceftriaxone (CRO) 30 $\mu$ g, (Liofilchem Co. Italy), were placed aseptically on the plates and pressed gently to the agar surface using sterile forceps then incubated at $35-37^{\circ} \mathrm{C}$ for 16-18 hours and examined for the inhibition zones. The size of the inhibition zones was compared with zone diameter recommended by CLSI screening criteria, as followed cefotaxime (CTX) screening breakpoint $\leq 27 \mathrm{~mm}$, ceftazidime $(\mathrm{CAZ}) \leq 22 \mathrm{~mm}$, aztreonam $($ ATM $) \leq 27 \mathrm{~mm}$, cefpodoxime $(\mathrm{PX}) \leq 22 \mathrm{~mm}$ and ceftriaxone $(\mathrm{CRO}) \leq 25$ $\mathrm{mm})$, were considered as potential ESBL producer [11].

\subsubsection{Double Disc Synergy Test (DDST)}

The double disc synergy test was carried out on MullerHinton agar plate seeded by bacterial suspension. A disc containing the amoxiclave (amoxicillin $20 \mu \mathrm{g}$ plus clavulanic acid $10 \mu \mathrm{g}$ ) was placed on the center of Muller-Hinton agar, four discs of the following cephalosporins; cefepeme $30 \mu \mathrm{g}$, ceftazidime $30 \mu \mathrm{g}$, cefotaxime $30 \mu \mathrm{g}$, and aztreonam $30 \mu \mathrm{g}$ were placed around amoxiclave (Augmentin 20/10 $\mu \mathrm{g}$ ) at distance $25 \mathrm{~mm}$ center to center. After overnight incubation, if there is an extension of the zone towards the disc containing amoxicillin-clavulanic acid it indicated that the strain possesses an ESBL [11].

\subsubsection{Double Disk Diffusion Test (DDDT)}

According to NCCLS, and CLSI-ESBL, phenotypic confirmatory test with Ceftazidime $30 \mu \mathrm{g}$, cefotaxime $30 \mu \mathrm{g}$, and cefepeme $30 \mu \mathrm{g}$ were performed for all the isolates by disk diffusion test (DDDT). Each disk was placed onMullerHinton agar plates with and without $10 \mu \mathrm{g}$ of clavulanic acid. A difference of $\geq 5 \mathrm{~mm}$ between the zone diameters of either of the cephalosporin disks and their respective cephalosporin/clavulanate disk was considered to be phenotypic confirmation of ESBL production [11]. E. coli strain ATCC 25922 was used as a negative control and Klebsiellapneumoniae ATCC 700603 was used as a positive control.

\subsection{Genotypic Detection of ESBLs}

\subsubsection{DNA Extraction}

The plasmid DNA was extracted using DNA extraction kits (iNtRON BIOTECHNLOGY, Seongnam, Korea), which was shown high quality and quantity of DNA collected from cultured gram-negative bacteria.

All isolates were screened for the resistance genes bleCTX-M, bleTEM, and bleSHV by polymerase chain reaction (PCR), with specific primers. The amplification was done using CONVGYS ${ }^{\circledR}$ td peltier thermal cycle $(\mathrm{Gmbh}$ and Co. KG, Germany). In a total reaction volume of 25 ulcontaining (5ul master mix of Maxime RT premix kit (iNtRON BIOTECHNOLOGY, Seongnam, Korea), 0.6 forward primer, 0.6 reverse primer, $2 \mathrm{ul}$ plasmid DNA and 16.8 ul deionized sterile water. Then thePCR mixture was subjected to initial denaturation step at $94^{\circ} \mathrm{C}$ for 5 -mint, followed by 30 cycles of denaturation at $94^{\circ} \mathrm{C}$ for 45 seconds, primer annealing at $57^{\circ} \mathrm{C}$ for 45 seconds, followed by step of elongation at $72^{\circ} \mathrm{C}$ for 60 seconds, thefinal elongation at $72^{\circ} \mathrm{C}$ for $5 \mathrm{mint}$. [12].

\subsubsection{DNA Sequencing for Characterization of CTX-M, TEM and SHV Genes}

Sequencing is a method for determining the nucleotide sequence of a DNA molecule, thus it is a very precise method. DNA purification and standard sequencing was performed for both strands of CTX-M, TEM and SHV genesby Macrogen Company (Seoul, Korea). Selected positive sample were sealed in sterile eppendorf tubes and sent to the DNA sequencing service in Seoul, Korea [13].

\subsubsection{Bioinformatics Analysis}

The sequences chromatogram was viewed by Finch TV program, (http://www.geospiza.com/Products/finchtv.shtml). Then the nucleotides sequences of the CTX-M, TEM and SHV beta-lactamases genes were searched for sequences similarity using nucleotide BLAST (http: //blast.ncbi.nlm.nih.gov/ Blast.cgi). Highly similar sequences were retrieved from NCBI and subjected to multiple sequence alignment using (http://www.phylogen.fr/simple.phylogeny.cgi) software [14].

\section{Results}

\subsection{Antibiotic Susceptibility Pattern of Gram Negative Bacilli}

Among the ESBL-producing Gram-negative bacilli, high resistance rates were observed for ceftriaxone (100.0\%), tetracycline $(100.0 \%)$, ciprofloxacin $(100.0 \%)$, amoxyclav (98.9\%), cefuroxime (98.9\%), nalidixic acid (98.9\%) andamoxicillin (95.5\%). The highest antimicrobial activities 
of ESBL-producing organisms were observed with amikacin (96.6\%), followed by Chloramphenicol (63.6\%), Tobramicin (53.4\%) and nitrofurantoin (50.0\%). ESBL-producing Gramnegative bacilli isolates were significantly more resistant to trimethoprim-sulfamethoxazole, tetracycline, nalidixic acid, cefuroxime, ceftazidime, ceftriaxone, ciprofloxacin, gentamicin, nitrofurantoin, amoxyclav, tobramicin and chloramphenicol compared to non-ESBL producing isolates.

\subsection{Phenotypic Detection of ESBLs}

A total of 198 Gram-negative bacilli isolates were tested for ESBL production. Of the 198 isolates, 94 (47.5\%) were found to be ESBL-producers by double-disk synergy test (DDST), and $88(44.4 \%)$ were detected using confirmatory double-disk diffusion test method (DDDT).

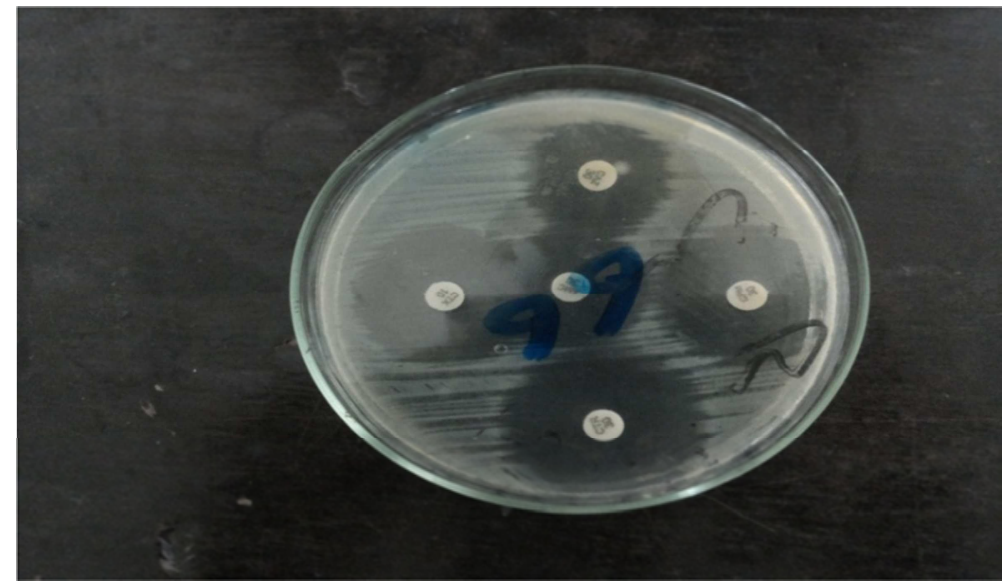

Figure 1. Double-disk synergy test (DDST), showing a clearextension ofthe edge of the inhibition zone of cephalosporin towards amoxicillin-clavulanic acid disk (augmentin) is interpreted as positive for ESBL production.

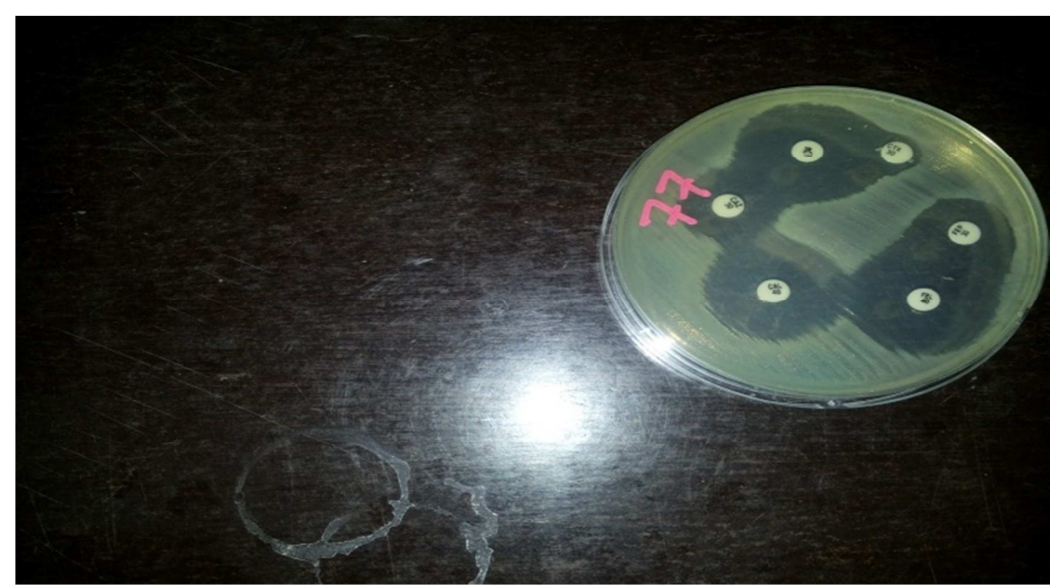

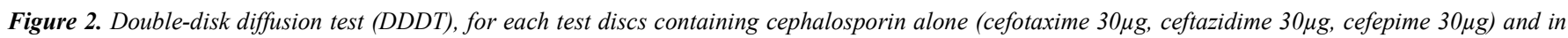

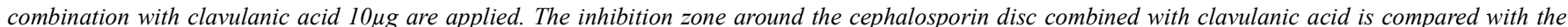
zone around the disc with the cephalosporin alone. The test is positive if the inhibition zone diameter is $\geq 5$ mm larger with clavulanic acid than without.

\subsection{Genotypic Detection of Extended-Spectrum B-lactamases (ESBL) Production}

Out of 88 isolates were subjected to PCR. Thegenotypic result (PCR result) confirmed the existence of. $73.9 \%(65 / 88)$ by PCR method, while $26.1 \%$ (23/88) was confirmed negative by PCR method.

The commonest prevalence of ESBL genes was CTX-M gene $53 / 88(60.2 \%)$. This was observed in $25 / 53$ isolates (47.2\%) of Escherichia coli, 6/53 isolates (11.3\%) of Klebsiellapneumoniae and $1 / 53$ isolate $(1.9 \%)$ of Proteus mirabilis. The difference in the prevalence of ESBL genes was significant. The following gene was TEM gene $22 / 88$ (25.0\%), and the least one was the SHV gene 13/88 (14.8\%).
Some isolates harbored two or more ESBL genes. Out of the 47 Escherichia coli isolates, 2 strains (4.3\%) harbored all CTX-M, TEM and SHV genes. While out of 14 Klebsiellapneumoniae isolates, 1 strain $(7.1 \%)$ harbored on CTX-M and SHV genes.

\subsection{Multiple Sequence Alignment}

The multiple sequence alignment of the mutant isolate with similar nucleotide sequences that obtained from BLASTn was carried out to find the homology and evolutionary relation between these sequences. As shown by BioEdit software there is an inserted and deleted of amino acid at very conserved region, see Figure: $(3,4,5)$. 


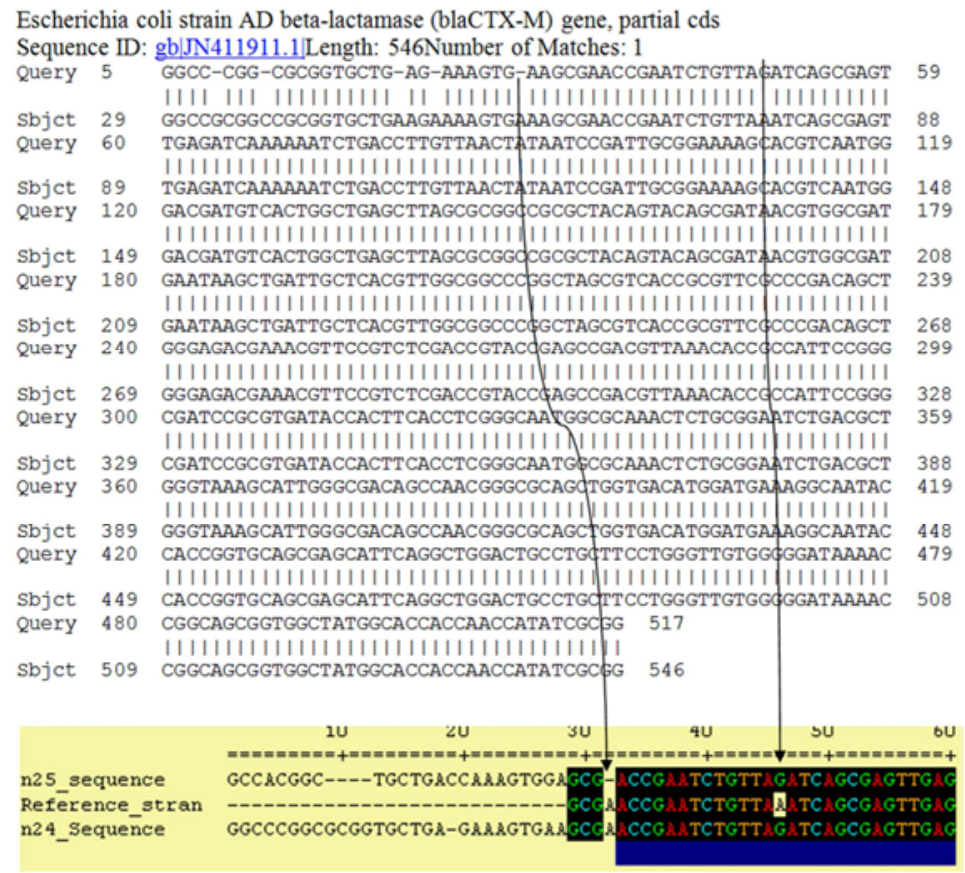

Figure 3. Sequencing alignment for Mutant CTX-M gene sequence chromatogram. CTX-M gene NO. 25 showed deletion of amino acid adenine at position 31, and substitution of amino acid adenineto guanine $(G-A)$ at position 49, compared to the reference sequence. While CTX-M gene NO. 24 showed a substitution of amino acid adenine to guanine $(G-A)$ at position 49 compared to the reference sequence.

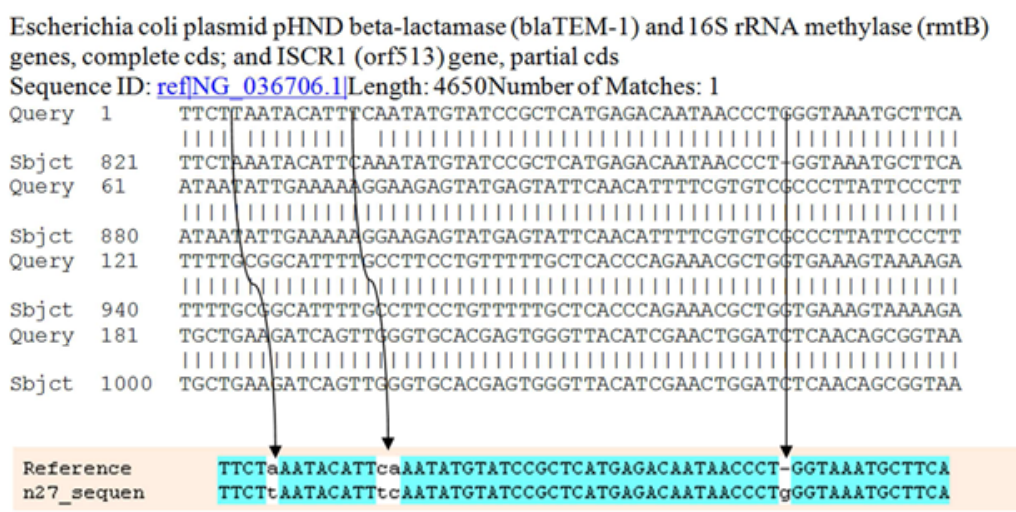

Figure 4. Sequencing alignment for Mutant TEM gene sequence chromatogram. TEM gene NO. 27 showed substitution of amino acid thymine to adenine (TA) at position 5, and substitution of amino acid thymine and cytosine to cytosine and adenine respectively at position 14, 15. And deletion of amino acid guanine at position 47 compared to the reference sequence.

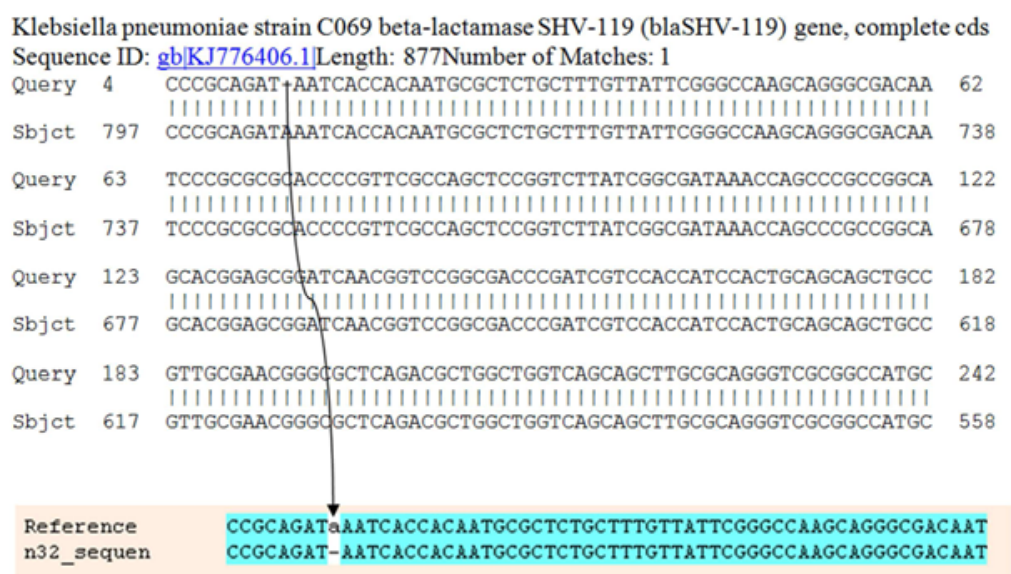

Figure 5. Sequencing alignment for Mutant SHV gene sequence chromatogram. SHV gene NO. 32 showed deletion ofamino acid adenine at position 9 compared to the reference sequence. 


\section{Discussions}

ESBL detection is not routinely carried out in many microbiology laboratories of hospitals in developing countries, as well as in Sudan. The emergence of ESBLproducing strains creates a need for laboratory testing methods for detection of these enzymes among bacterial pathogens [15].

In the present study, ESBL-producers were detected phenotypically by DDST and the phenotypic DDDT confirmatory method. The DDDT test was compared with DDST and it was found to be an inexpensive alternative for the DDST, for the detection of ESBL producers. The DDST lacks sensitivity because of the problem of optimal disc space and the correct storage of the clavulanic acid containing discs. Thereforethe Clinical and Laboratory Standards Institute (CLSI) are recommended the use of DDDT for the phenotypic confirmation of the ESBL producers among Gram-negative bacilli. But these both tests were yielded an equal accuracy in the determination of ESBL production. These methods had been previously documented as effective tests for detection of ESBL-producers by other authors. Moreover, these both tests are available and simple to apply routinely along with antimicrobial susceptibility test in our hospital [16].

In this study the EBSL phenotypes were detected $44.4 \%$ isolate and confirmed by DDDT method. Non EBSL phenotypes were detected among $55.6 \%$ of the isolates studied. This figure is nearly to that figure reported in Sudan where ESBL producerswere 40\% [17]., 2012). While this figure is low compared to the figure reported in a study carried out in Khartoum State hospitals where ESBL productions among Gram-negative isolates were 53\% [18]. Also lower than the $60.9 \%$ observedin Egypt [19]. And $61.6 \%$ reported in India [20]. But, the current study findings are similar to that obtained in Sudan where Gram-negative isolateswere 45\% [21]. But, much higher than the $6.5 \%$ reported in Saudi Arabia [22]. In addition, the observed prevalence of $44.4 \%$ in the current study is much higher compared to those reported in Europe, USA and Canada [23]. Overall, these findings indicate that the prevalence of bacteria producing-ESBL varies worldwide.

The present study determined high resistance rates among ESBL-producing strains to first line antimicrobial therapy such as amoxicillin, trimethoprim-sulfamethoxazole, tetracycline, nalidixic acid ciprofloxacin and amoxicillinclavulanic acid. Similar rates of resistance have been previously reported in Sudan [24]. Other developing countries [25]. Significantly high rates of resistance to such commonly used oral antimicrobials have been previously described making these agents clinically ineffective for empirical treatment of infection caused by ESBL-producing strains [26].

Whilst the cephalosporins such as, cefuroxime, ceftriaxone and ceftazidime have been used to treat Gram-negative bacterial infections of various body sites [27]. In this study, higher resistance rates were observed among isolated strains for ceftriaxone (100\%) ( $p$ 0.00) and cefuroxime (98.9\%) ( $p$ 0.002). A similar study inSaudi Arabia conducted ESBLproducing strains were found to show high resistance to ceftriaxone [28]. The high percentage of resistance to third generation cephalosporins notably to ceftriaxone is of great concern, since it was found to be much higher than those reported in other parts of the world [28]. A possible explanation for the high resistance might be due to unappropriate use of these drugs, or the presence of extended spectrum $\beta$-lactamases enzymes (ESBL). Since, ESBL mediated resistant to $\beta$-lactam antimicrobials of penicillin and cephalosporins groups as well as other classes of antimicrobial agents, it is therefore important that routine screening of ESBL in clinical isolates is carried out to prevent widespread of resistant isolates in our hospital.

In the present study genotypic screening of $88 / 198$ (44.4\%) confirmed ESBL phenotype strains by P.C.R had revealed $65 / 88$ (73.9\%) frequency rate positive genotypes for at least one of studied genes. While $26.1 \%$ of positive phenotype ESBL strains lacked CTX-M, TEM and SHV genes. This can be explained by the possible presence of other ESBL encoding genes in the bacterial isolates studied. More genotypes were found among E. coli 47/65 (72.3\%) and $K$. pneumonia $14 / 65(21.5 \%)$ in a similar finding reported by Moosavian and Deiham., (2012) [30]. found more positive genotypic strains in E. coli and K. pneumoniae (79.5\%). Out of $65(73.9 \%)$ isolated genes. CTX-M gene was occurred at highest frequency $53 / 88(60.2 \%)$. This result is in-agreement with that reported by Quinteroset al., (2003) [31]. However, it has been reported that the proportion of CTX-M strains among ESBL-producing isolates had dramatically increased from $38.2 \%$ to $87 \%$ worldwide [31]. Less CTX-M prevalence was reported in study carried out in Tehran republic of Iran [32]., and Korea [33]. Also in this study showed that CTX-M gene was most common encountered in E. coli with an account of $25 / 53(47.2 \%)$. This is in-agreement with the reports by Sekaret al [34]. in India, who detected that $44.4 \%$ was $E$. coli. Butthis figure is low compared to the figure reported by Eltayeb $\mathrm{HN}$ et al [35]. in Sudan, who recorded CTX-M gene among E. coli was $(65.2 \%)$. In addition, the observed prevalence of CTX-M gene $(47.2 \%)$ among $E$. coli in the current study is much lower compared to that reported by Kola, et al [36]., who found to be $(70 \%)$. The spread of CTX-M had also been described through prospective studies in industrialized countries such as Canada, France and United Kingdom [37]. The TEM was a second ESBL gene among isolates (25.0\%). This is similar to that reported by Al-azawyet al [7]. in Sudan, who found to be (22.2\%). But less than that $(72.0 \%)$ reported by Hosoglu et al. [38] In our study the SHV was less frequent gene $(14.8 \%)$. Also this result is in-agreement to that (16.7\%) reported by Al-azawyet al., (2012) [7]. in Sudan.

The result in this study showed that the prevalence rate of SHV-type ESBL among E. coli strains and among $K$. 
pneumoniae strains were $13.4 \%$ and $13.3 \%$ respectively. This result is higher than that obtained by Eltayeb $\mathrm{HN}$ et al [7], who reported that $6.5 \%$ was SHV gene among $E$. coli strains.

In our study the BLASTn searchingand phylogeny fr.multiple sequence alignment revealedan insertion, deletion and substitution of amino acids to the different genes of CTX-M, TEM and SHV, at very conserved region. This mutation may be the cause of ESBL activity, because this mutation located at beta-lactamase/transpeptidase-like domain which is the penicillin-binding domain of PBPs, that function as DD-transpeptidases, its catalyze the final step of cell wall biosynthesis by cross-linking two strands of peptidoglycan, or DD-peptidases. Similar explanation has been discussed by Eltayeb HN et al [39].

\section{Conclusions}

ESBL types CTX-M, TEM and SHV genes are predominant among Gram-negative bacilli isolates and ESBL producer strains carried one or more than CTX-M, TEM or SHV gene. ESBLs genes are rapidly evolved among pathogenic bacteria, thus study like this to detect a new antibiotic resistant gene variants could guide the choice of optimal antibiotic therapy for successful treatment, thus improving the outcomes for patients with severe bacterial infections.

\section{Acknowledgements}

The authors kindly thank the staff and students of Port Sudan Ahlia Collage, Sudan. We acknowledge at the Departments of Microbiology Laboratories of participating Port Sudan teaching hospital for their support in sample collection. And also we acknowledge Ms. Suhair Ramadan from Sudan University of science and technology for her support.

\section{References}

[1] Ahmed AA, Osman H, Mansour AM, Musa HA, Ahmed AB, Karrar Z. Antimicrobial agents' resistance in bacterial isolates from patients with diarrhea and urinary tract infection in the Sudan. The American Journal of Tropical Medicine and Hygiene 2000; 63: 259-263.

[2] Ahmed, O. B., Omar, A. O., Asghar, A. H., Elhassan, M. M., \& Al-Munawwarah, A. M. Prevalence of TEM, SHV and CTX-M genes in Escherichia coli and Klebsiella spp. Urinary Isolates from Sudan with confirmed ESBL phenotype. Life Sci. J 2013; 10(2), 191-195.

[3] Ajiboye RM, Solberg OD, Lee BM, Raphael E, Debroy C and Riley LW. Global spread of mobile antimicrobial drug resistance determination in human and animal Escherichia coli and Salmonella strains causing community acquired infections: Clinical infection Diseases 2009; 49: 365-371.

[4] Aktas Z., Kayacan C. B., Schneider I., Can B., Midilli K., Bauernfeind A. Carbapenem hydrolyzing oxacillinase, OXA48, persists in Klebsiellapneumoniaein Istanbul, Turkey.
Chemotherapy 2008; 54(2): 101-106.

[5] Al Benwan K., Al Sweih N., Rotimi V. O. Etiology and antibiotic susceptibility patterns of community and hospital acquired urinary tract infections in a general hospital in Kuwait. Med. Princ. Pract. 2010; 19(6): 440-446.

[6] Al-Agamy M. H. Mohamed, El-Din Ashour M. S., Wiegand I. First description of CTXM beta-lactamase-producing clinical Escherichia coli isolates from Egypt. Int. J. Antimicrob. Agents. 2006; 27(6): 545-548.

[7] Al-azawy, A. F. K. A. S. Humodi."Phenotypic Detection and Molecular Characterization of Extended Spectrum BLactamases in Enterobacteriaceae Isolated from Khartoum Hospitals." PhD diss. Sudan Journal of Science and Technology 2012; ISSN: 1858—6716.

[8] Alsterlund R., Carlsson B., Gezelius L., Haeggman S., Olsson-Liljequist B. Multi resistant CTX-M-15 ESBLproducing Escherichia coli in southern Sweden: description of an outbreak. Scand. J. Infect. Dis. 2009; 41(6-7): 410-415.

[9] Al-Zahrani, A. J., Akhtar, N. Susceptibility Patterns of Extended Spectrum $\beta$-Lactamase (ESBL)-producing Escherichia coli and Klebsiellapneumoniae isolated in a teaching hospital. Pakistan J. Med. Res 2005; 44(2): 64-67.

[10] Cheesbrough M. District Laboratory Practiceintropical Countries, Part II, Cambridge university press, UK, 2000; chapter 7, pp 36-37-38-167.

[11] Clinical and Laboratory Standards Institute. Performance standards for antimicrobial disk susceptibility tests; twenty first Informational supplements. CLSI document M100-S21, Wayne, Pa: Clinical and Laboratory Standards Institute 2013; 31(1).

[12] Coque T. M., Baquero F., Canton R. Increasing prevalence of ESBL-producing Enterobacteriaceae in Europe. Euro. Surveill. 2008; 13(47): 1-11.

[13] Delela G, GuptaS, Jain DK, Mehta P. Antibiotic Resistance Pattern in Uropathologensis at a Tertiary Care Hospital at Jhalawar with special Reference to ESBL, Ampc b-lactamases and Mrsa Production. J Clin DR 2012; 6(4): 645-651.

[14] Dereeper A., Audic S., Claverice J. M., Blanc G. BLASTEXPLORER helps you building datasets for phylogenetic analysis. BMC EvolBiol 2010; (PubMed).

[15] Moyo SJ, Aboud S, Kasubi M, Lyamuya EF, Maselle SY. Antimicrobial resistance among producers and non-producers of extended spectrum beta-lactamases in urinary isolates at a tertiary Hospital in Tanzania. BMC Res Notes 2010; 3: 348.

[16] Tschudin-Sutter S, Frei R, Battegay M, Hoesli I, Widmer AF. Extended spectrum $\beta$-lactamase-producing Escherichia coli in neonatal care unit. Emerg Infect Dis 2010; 16(11): 1758-1760.

[17] Al-azawy, A. F. K. A. S. Humodi."Phenotypic Detection and Molecular Characterization of Extended Spectrum BLactamases in Enterobacteriaceae Isolated from Khartoum Hospitals." PhD diss. Sudan Journal of Science and Technology 2012; ISSN: 1858-6716.

[18] Mekki AH, Hassan AN, Elsayed DE. Extended spectrum beta lactamases among multi drug resistant Escherichia coli and Klebsiella species causing urinary tract infections in Khartoum. Journal of Bacteriology Research 2010; 2 (3): 18-21. 
[19] Mohamed Al-Agamy MH, El-Din Ashour MS, Wiegand I. First description of CTX-M beta-lactamase-producing clinical Escherichia coli isolates from Egypt. Int J Antimicrob Agents 2006; 27(6): 545-548.

[20] Delela G, GuptaS, Jain DK, Mehta P. Antibiotic Resistance Pattern in Uropathologensis at a Tertiary Care Hospital at Jhalawar with special Reference to ESBL, Ampc b-lactamases and Mrsa Production. J Clin DR 2012; 6(4): 645-651.

[21] Eltayeb HN and Hamedelnil, F. Y. Molecular detection of Extended Spectrum $\beta$-lactamases (ESBLs) genes in E. coli isolated from urine specimen, Sennar State, Sudan. International $\mathrm{J}$ of advanced scientific and technical research 2012; 5(2): ISSN 2249_9954.

[22] Kader, A. A., Angamuthu, K, K., Kamath, K. A, and Zaman, M. N. Modified double-disc test for detection of extendedspectrum $\beta$-lactamases in Escherichia coli and Klebsiellapneumoniae. British Journal of Biomedical Science 2006; 63: 4; 51-54.

[23] Dhillon RH, Clark J. ESBLs: A Clear and Present Danger? Crit Care Res Pract 2012; 625170.

[24] Ahmed AA, Osman H, Mansour AM, Musa HA, Ahmed AB, Karrar Z. Antimicrobial agents' resistance in bacterial isolates from patients with diarrhea and urinary tract infection in the Sudan. The American Journal of Tropical Medicine and Hygiene 2000; 63: 259-263.

[25] AminizadehZandKashi MS. Prevalence of multi-drug resistance and pan drug resistance among multiple gramnegative species: experience in one teaching hospital, Tehran, Iran: International Research Journal of Microbiology 2011; 2: 90-95.

[26] Namboodiri SS, Opintan JA, Lijek RS, Newman MJ and Okeke IN. Quinolone resistance in Escherichia coli from Accra, Ghana: BMC Microbiology 2011; 11: 44.

[27] Sahuquillo-Arce JM, Selve M, Perpin H, Gobernado M, Armero C, Lopez-Quilez A. Antimicrobial Resistance in More than 100,000 Escherichia coli Isolates According to Culture Site and Patient Age, Gender, and Location: Antimicrobial agents and Chemotherapy 2011; 1222-1228.

[28] Al-Zahrani, A. J., Akhtar, N. Susceptibility Patterns of Extended Spectrum $\beta$-Lactamase (ESBL)-producing Escherichia coli and Klebsiellapneumoniae isolated in a teaching hospital. Pakistan J. Med. Res 2005; 44(2): 64-67.

[29] Mohammadtaheri Z, Pourpaki M, Mohammadai F, Namdar R and Masjedi MR. Surveillance of Antimicrobial Susceptibility among Bacterial Isolates from Intensive Care Unit Patients of a Tertiary-Care University Hospital in Iran: Chemotherapy 2010; 56: 478-484.
[30] Moosavian M and Deiham B. Distribution of CTX-M, TEM and SHV gene among ESBL-producing Enterobacteriaceae Isolate in Iran Afr. J Microbiol. Res 2012; 6 (26): 5433-5439.

[31] Quinteros, M, Radice M, Gardella N, Rodriguez M. M, Costa N, Korbenfeld D, Couto E, and Gutkind G. Extended spectrum beta-lactamases in Enterobacteriaceae in Buenos Aires, Argentina, public hospitals. Antimicrob Agents Chemother 2003; 47: 2864-2867.

[32] Feizabadi MM, Delfani S, Raji N, Majnooni A, Aligholi M, Shahcheraghi F, Parvin M and Yadegarinia D. Distributionof bla (TEM), bla (SHV), bla (CTX-M) genes among clinical isolates of Klebsiella pneumonia at Labbafinejad Hospital, Tehran, Iran. Microbial drug resistance 2010; 16(1): 49-53.

[33] Chaibi EB., Sirot D., Paul G. and Labia R. Inhibitor Resistant TEM beta-lactamases: phenotype, genetic and biochemical characteristics. J AntimicrobChemother 1999; 43: 447-458.

[34] Sekar B, Shwetha R, Arunagiri K, Menaka K, Lalitha P, Aparna V. Detection and characterization of bla CTX-M gene by PCR-RFLP analysis among third generation cephalosporin resistant gram negative isolates. XXX National Congress of Indian Association of Medical Microbiologists. Microconi 2006; P. 27

[35] Eltayeb HN and Hamedelnil, F. Y. Molecular detection of Extended Spectrum $\beta$-lactamases (ESBLs) genes in E. coli isolated from urine specimen, Sennar State, Sudan. International $\mathrm{J}$ of advanced scientific and technical research 2012; 5(2): ISSN 2249—9954.

[36] Kola A, Holst M, Chaberny IF, Ziesing S, Suerbaums, Gastmeier P. Surveillance of extended-spectrum betalactamase-producing bacteria and routine use of contact isolation: experience from a three year period. J Hosp Infect 2007; 66: 46-51.

[37] Ruppe, E., Hem, S., Lath, S., Gautier, V., Ariey, F., Sarth OV, J. L., Monchy, D., Arlet G. CTX-M $\beta$-lactamases in E. coli from community acquired Urinary Tract Infection. Cambodia. EmergInfet Dis 2009; 15 (5): 741-745.

[38] Hosoglu S, Gundes S, kolayli F, karadenizli A, Demirdag K, Gunaydin M, Altindis M, Caylan R, and Ucmak H. Extendedspectrum beta-lactamases in ceftazidime - resistant Escherichia coli and Klebsiella pneumonia isolates in Turkish hospitals. Indian J Med Microbiol 2007; 25(4): 346-350.

[39] Eltayeb HN, M. El Amin. Nagwa. Maowia M. Mukhtar. A M Siddig. Mohamed. Molecular Characterization and in Silico Analysis of a Novel Mutation in TEM-1 Beta-Lactamase Gene among Pathogenic E. coli infecting a Sudanese Patient. American Journal of Microbiological Research 2014; 6(2) 217-223. 